\title{
Vaginal delivery at term with previous one cesarean section: is it safe?
}

\author{
Surendra N. Bera, Partha P. Sharma*
}

Department of Obstetrics and Gynecology, Midnapore Medical College, Paschim Medinipur, West Bengal, India

Received: 16 May 2018

Revised: 12 June 2018

Accepted: 23 June 2018

\section{*Correspondence:}

Dr. Partha P. Sharma,

E-mail: parthap_sharma@yahoo.co.in

Copyright: () the author(s), publisher and licensee Medip Academy. This is an open-access article distributed under the terms of the Creative Commons Attribution Non-Commercial License, which permits unrestricted non-commercial use, distribution, and reproduction in any medium, provided the original work is properly cited.

\begin{abstract}
Background: Post cesarean pregnancies are high risk pregnancy and main concern is uterine scar rupture with increasing maternal and perinatal risks, for vaginal birth after cesarean delivery (VBAC). Objective of this study is to know neonatal and maternal outcome at term who attempt vaginal delivery with previous one cesarean section presenting in active stage of labor.

Methods: A total of 277 pregnant women with single live fetus at term, cephalic presentation with previous one cesarean section, underwent a trial of labor and outcome of successful and failed vaginal birth were noted.

Results: Trial of labor was successful in $52.3 \%$ and failed in $47.7 \%(\mathrm{p}=0.269)$. VBAC was successful where the previous cesarean section indications were fetal distress $(79 \%$ versus $21 \%, \mathrm{p}=0.000)$, pregnancy induced hypertension (77.3\% versus $22.7 \%, \mathrm{p}=0.000)$ and fetal growth restriction $(81.8 \%$ versus $18.2 \%, \mathrm{p}=0.000)$, when compared with failed trial of labor who required emergency cesarean section in pre-labor rupture of the membranes $(8.3 \%$ versus $91.7 \%, \mathrm{p}=0.000)$ and dystocia $(3.3 \%$ versus $96.7 \%, \mathrm{p}=0.000)$. VBAC was successful at gestational age of 37 0/7-38 $6 / 7$ weeks $(\mathrm{p}=0.000)$. In the failed VBAC women who required emergency cesarean section there was significant early neonatal death $(\mathrm{p}=0.025)$. Scar dehiscence and hospital stay with or without complications were more in the failed VBAC group.

Conclusions: Early neonatal death and duration of hospital stay were significantly more in the failed VBAC, who were posted for emergency cesarean delivery. Scar dehiscence occurred in the failed VBAC group. Women presenting at $370 / 7$ to 38 6/7 weeks of gestation with cephalic presentation in active stage of labor who had previous cesarean section done for fetal distress, pregnancy induced hypertension and fetal growth restriction with inter pregnancy interval of $>24$ months can be planned and counselled for VBAC trial of labor.
\end{abstract}

Keywords: Cesarean section, Neonatal and maternal outcome, Scar dehiscence, VBAC at term

\section{INTRODUCTION}

Pregnancy with prior cesarean delivery is quite prevalent in present day obstetric practice, these cases are loosely called 'post cesarean pregnancy'.

Women undergoing a trial of labour after caesarean experienced a uterine rupture of $0.2 \%-0.3 \% .^{1}$ Perinatal morbidity was found not significant in a carefully selected cases for trial of labor after cesarean. ${ }^{2}$ Scar tenderness has been a major cause of repeat sections. All women who have experienced a prior cesarean birth should be counselled about the maternal and perinatal risk, and benefits of planned vaginal birth after cesarean (VBAC) and elective repeat cesarean section (ERCS) when deciding the mode of birth. Main objective of this clinical study is to analyse neonatal and maternal outcome at term, who attempt vaginal delivery with previous one cesarean section presenting with cephalic presentation in active stage of labor. 


\section{METHODS}

This observational study was undertaken in the department of obstetrics and gynaecology for a period of one year and six months in collaboration with department of paediatrics, anaesthesia and critical care unit. Authors have blood bank facility, HDU and neonatal intensive care unit in present hospital. Authors have considered women for VBAC trial who went into spontaneous labor at term with cervical dilatation of $4 \mathrm{~cm}$ or above and outcome of both mother and baby were noted. Women were counselled nearing at term for intended VBAC trial. Inclusion criteria were single live fetus at term with previous one cesarean section and on admission who has no evidence of scar tenderness, cephalic presentation and in active stage of labor likely to deliver vaginally. Exclusion criteria were gestational age $<37$ weeks and $\geq 42$ weeks, $\geq 2$ previous cesarean section, intra uterine fetal death, history of rupture uterus, multiple uterine surgery, classical cesarean section, primary indication of cesarean section was placenta previa and contracted pelvis and other contraindication for vaginal delivery and who are not willing to participate in the study and not giving consent. On admission detailed information regarding antenatal check-up, age, parity, literacy, socio economic status was noted. Clinical, abdominal and pelvic examination were done. Antenatal investigations like $\mathrm{ABO}$ grouping and $\mathrm{RH}$ typing, complete hemogram, blood sugar, VDRL, hepatitis B surface antigen, human immunodeficiency virus rapid test, routine and microscopic examination of urine and ultrasonography for feto-placenta profile were noted. A total of 277 pregnant women at term who fulfil the study criteria and gave consent are put in the VBAC trial of labor. Women were closely supervised by obstetrician and trained nursing staff with record of all vitals and progress of labor. Blood was arranged after proper grouping and cross matching for women with anemia or if cesarean section was contemplated. During post-partum period the condition of the mother and baby were observed.

\section{Statistical analysis}

After completion of the study all the data of maternal and neonatal outcome of both successful and failed trial of labor group who required emergency cesarean section were entered in MS Excel 2007 software after thorough verification and cleaning. Data analysis was done using SPSS software package (18 version). Comparison of proportion between the two groups were assessed by chisquare test and that of mean were done by t test. For all statistical purposes, $\mathrm{p}<0.05$ was taken as statistically significant. In some cells, values are <5; thus, Yate's correction done.

\section{RESULTS}

There were 17105 deliveries during the study period out of which 1280 were post cesarean pregnancy. Among them a total of 277 post cesarean pregnant women who fulfil the study criteria with singleton pregnancy at term underwent a trial of labor, of which 145 women had successful VBAC $(52.3 \%)$ and 132 women had failed VBAC $(47.7 \%)$ who required emergency cesarean delivery $(\mathrm{p}=0.269)$.

Table 1: Present mode of delivery in relation to previous cesarean delivery indications.

\begin{tabular}{|c|c|c|c|c|}
\hline \multirow{2}{*}{$\begin{array}{l}\text { Indications for previous } \\
\text { cesarean delivery }\end{array}$} & \multicolumn{2}{|c|}{ Mode of delivery } & \multirow[b]{2}{*}{$\chi^{2}$ value } & \multirow[b]{2}{*}{ P-value } \\
\hline & $\begin{array}{l}\text { Vaginal delivery } \\
(n=145)\end{array}$ & $\begin{array}{l}\text { Emergency cesarean } \\
\text { delivery }(n=132)\end{array}$ & & \\
\hline Fetal distress (62) & $49(79 \%)$ & $13(21 \%)$ & 41.81 & 0.000 \\
\hline Breech (54) & $28(51.9 \%)$ & $26(48.1 \%)$ & 0.148 & 0.700 \\
\hline $\begin{array}{l}\text { Pregnancy induced } \\
\text { hypertension (44) }\end{array}$ & $34(77.3 \%)$ & $10(22.7 \%)$ & 26.18 & 0.000 \\
\hline Fetal growth restriction (22) & $18(81.8 \%)$ & $4(18.2 \%)$ & 15.36 & $0.000^{*}$ \\
\hline Elderly primi (4) ${ }^{\#}$ & 0 & $4(100 \%)$ & & \\
\hline Post-dated (28) & $12(42.9 \%)$ & $16(57.1 \%)$ & 1.14 & 0.285 \\
\hline Dystocia (30) & $1(3.3 \%)$ & $29(96.7 \%)$ & 48.6 & $0.000 *$ \\
\hline $\begin{array}{l}\text { Prelabor rupture of the } \\
\text { membranes }(24)\end{array}$ & $2(8.3 \%)$ & $22(91.7 \%)$ & 30.08 & $0.000^{*}$ \\
\hline Transverse lie (1) $\#$ & 0 & $1(100 \%)$ & & \\
\hline Oblique lie (8) & $2(25 \%)$ & $6(75 \%)$ & 2.25 & $0.134 *$ \\
\hline Total (277) & $145(52.3 \%)$ & $132(47.7 \%)$ & 1.22 & 0.269 \\
\hline
\end{tabular}

*Yate's corrected $\mathrm{P}$ value; ${ }^{*} \chi^{2}$ not valid

For successful VBAC, non-recurrent indication of previous cesarean delivery had more favourable outcome in the present study (Table 1). The percentage of successful VBAC women in the present study (Table 1) was significant $(\mathrm{P}=0.000)$ where the previous cesarean delivery indications were fetal distress, pregnancy induced hypertension and fetal growth restriction. And the percentage of failed VBAC women who required 
emergency cesarean delivery in the present study was significant $(\mathrm{P}=0.000)$, where the previous cesarean done for pre-labor rupture of the membranes and dystocia as shown in the Table 1.

Table 2 shows VBAC was successful at gestational age of $370 / 7$ to $386 / 7$ weeks $(p=0.000)$, whereas the percentage of failed VBAC was significant when compared with successful VBAC at gestational age of 39 $0 / 7$ to $406 / 7$ weeks $(\mathrm{p}=0.007)$ and $410 / 7$ to $416 / 7$ weeks $(\mathrm{p}=0.000)$.

Table 2: VBAC in relation to gestational age $(n=277)$.

\begin{tabular}{|llll|}
$\begin{array}{l}\text { Gestational } \\
\text { age (weeks) }\end{array}$ & $\begin{array}{l}\text { Successful } \\
\text { VBAC } \\
(\mathbf{n = 1 4 5})\end{array}$ & $\begin{array}{l}\text { Failed } \\
\text { VBAC } \\
(\mathbf{n = 1 3 2})\end{array}$ & P-value \\
\hline $370 / 7-386 / 7$ & $102(70.3 \%)$ & $41(31.1 \%)$ & 0.000 \\
\hline $390 / 7-406 / 7$ & $38(26.2 \%)$ & $55(41.7 \%)$ & 0.007 \\
\hline $410 / 7-416 / 7$ & $5(3.5 \%)$ & $36(27.3 \%)$ & 0.000 \\
\hline
\end{tabular}

Of all trial of labor women,7.9\% (22/277) had 24 months or less interval between previous cesarean delivery and present pregnancy, whereas $92.1 \%(255 / 277)$ women had interval of more than 24 months in the present study (Table 3). An inter-delivery interval of $\leq 24$ months of gestation was associated with a rate of uterine scar dehiscence of $18.18 \%$ (4/22) found at cesarean section, compared to $3.13 \%(8 / 255)$ at interval of $>24$ months gestation $(\mathrm{p}=0.005)$.

Table 3: Inter-delivery interval and scar dehiscence.

\begin{tabular}{|llll|}
$\begin{array}{l}\text { Interval } \\
\text { (months) }\end{array}$ & $\begin{array}{l}\text { Number } \\
(\mathrm{n}=277)\end{array}$ & $\begin{array}{l}\text { Scar dehiscence } \\
(\mathrm{n}=12)^{\#}\end{array}$ & $\begin{array}{l}\text { P- } \\
\text { value }\end{array}$ \\
\hline$\leq 24$ & $22(7.94 \%)$ & $4(33.33 \%)$ & 0.013 \\
\hline $25-36$ & $88(31.76 \%)$ & $3(25 \%)$ & 0.860 \\
\hline $37-48$ & $135(48.74 \%)$ & $3(25 \%)$ & 0.188 \\
\hline$>48$ & $32(11.55 \%)$ & $2(16.67 \%)$ & 0.936 \\
\hline
\end{tabular}

\#Scar dehiscence in the failed VBAC women; *Yate's corrected $\mathrm{p}$ value

Early neonatal death was significant in the failed VBAC women who required emergency surgical intervention to deliver the fetus when compared with successful VBAC $(p=0.025)$. Number of other neonatal morbidities in both the groups were shown in the Table 4.

Table 4: Neonatal outcome in present pregnancy.

\begin{tabular}{|c|c|c|c|c|}
\hline $\begin{array}{l}\text { Nature of morbidity and } \\
\text { mortality }^{\#}\end{array}$ & $\begin{array}{l}\text { Successful VBAC } \\
(n=145)\end{array}$ & $\begin{array}{l}\text { Failed VBAC } \\
(\mathrm{n}=132)\end{array}$ & $\chi^{2}$ value & P-value \\
\hline Apgar scores at 1 minute $<7$ & $3(2.07 \%)$ & $6(4.55 \%)$ & 0.675 & 0.411 \\
\hline $\begin{array}{l}\text { Hypoxic ischemic } \\
\text { encephalopathy }\end{array}$ & $3(2.07 \%)$ & $6(4.55 \%)$ & 0.675 & 0.411 \\
\hline Birth injury & $4(2.76 \%)$ & 0 & & \\
\hline Jaundice & $2(1.38 \%)$ & $4(3.03 \%)$ & 0.28 & 0.596 \\
\hline Sepsis & $1(0.69 \%)$ & $2(1.52 \%)$ & 0.007 & 0.935 \\
\hline Respiratory infections & $1(0.69 \%)$ & 0 & & \\
\hline Congenital anomaly & $1(0.69 \%)$ & 0 & & \\
\hline Early neonatal death & $2(1.38 \%)$ & $10(7.58 \%)$ & 4.99 & 0.025 \\
\hline Total & $17(11.72 \%)$ & $28(21.21 \%)$ & & \\
\hline
\end{tabular}

\#Morbidity and mortality are not mutually exclusive; *Yate's corrected P value

Table 5: Maternal morbidity in VBAC trial of labor.

\begin{tabular}{|c|c|c|c|}
\hline Maternal morbidity ( $n=277)$ & Successful VBAC (n=145) & Failed VBAC $(n=132)$ & P-value \\
\hline Post-partum haemorrhage & $4(2.76 \%)$ & 0 & \\
\hline Scar dehiscence & 0 & $12(9.09 \%)$ & \\
\hline Sepsis & 0 & $2(1.52 \%)$ & \\
\hline Adherent placentae & $1(0.69 \%)$ & 0 & \\
\hline Chorioamnionitis & $1(0.69 \%)$ & 0 & \\
\hline Pyrexia & $4(2.76 \%)$ & $2(1.52 \%)$ & 0.767 \\
\hline Secondary suturing & 0 & 0 & \\
\hline Respiratory tract infections & $1(0.69 \%)$ & $1(0.76 \%)$ & 1.000 \\
\hline Abdominal distension & $1(0.69 \%)$ & 0 & \\
\hline Hysterectomy & 0 & $2(1.52 \%)$ & \\
\hline Blood transfusion & $4(2.76 \%)$ & $4(3.03 \%)$ & 1.000 \\
\hline \multicolumn{4}{|c|}{ Mean duration of hospital stay in days } \\
\hline With complication & $3.2 \pm(0.6)$ & $9.9 \pm(1.4)$ & 0.000 \\
\hline Without complication & $2.5 \pm(0.9)$ & $7.1 \pm(0.9)$ & 0.000 \\
\hline
\end{tabular}


Table 5 shows maternal morbidity in the present study. All cases of scar dehiscence occurred in the failed VBAC group, who has undergone emergency caesarean delivery (12/132). Post-partum haemorrhage occurred in the 4 women of successful VBAC trial group and all required blood transfusion. In the failed VBAC women blood transfusion required for preexisting anemia. Duration of hospital stay with or without complication was significant in the present study, when successful VBAC compared with failed VBAC who has undergone surgical intervention $(\mathrm{t}=50.89, \mathrm{p}=0.000$ and $\mathrm{t}=51.88, \mathrm{p}=0.000)$.

\section{DISCUSSION}

The American College of Obstetricians and Gynecologists (ACOG) has published recommendations for a trial of labor in low-risk patients in the appropriate settings. ${ }^{3}$ The bulletin states that candidate for VBAC should have no more than one prior lower segment cesarean delivery, a clinically adequate pelvis and no other uterine scars or previous rupture. RCOG recommended, Green-top guideline no. 45 October 2015 states that planned VBAC is a clinically safe choice for the majority of women with a singleton pregnancy of cephalic presentation at $37+0$ weeks or beyond with a single previous lower segment caesarean delivery. ${ }^{4}$ Gestational age $>40$ weeks alone does not preclude 'TOLAC' as per ACOG 2017 guidelines. Tessmer et al concluded that VBAC success was independently associated with age <30 years. ${ }^{5}$ In the present study authors also found that maximum women (163/277, $58.8 \%$ ) were belonged to age group of 26 to 30 years. Majority $(240 / 277,86.6 \%)$ women were para 1 . Most $(156 / 277,56.3 \%)$ women belonged to low socioeconomic status. Table 1 shows indication of previous cesarean section was one of the most important factor in deciding the mode of delivery in present pregnancy. Out of 277 pregnancy, the common indication of previous cesarean sections was fetal distress (62/277, 22.38\%), breech (54/277, 19.49\%), pregnancy induced hypertension (44/277, 15.88\%), dystocia (30/277, $10.83 \%)$ and postdated $(28 / 277,10.10 \%)$.

Among previous indications, malpresentation was associated with a high trial of labor success rate (74.51\%), whereas previous caesarean for fetal distress resulted in success in $67.34 \%$ cases. $^{2}$ In present study women with prior cesarean for fetal distress, pregnancy induced hypertension and fetal growth restriction had significant success for trial of vaginal delivery (Table 1), though in the above mentioned study by Balachandran et al recorded that no significant association was found between the indication for previous caesarean and the outcome of trial of scar. ${ }^{2}$ Previous indication as failure to progress resulted in lower success rates $(46.15 \%)$ in the trial of labor as recorded by Balachandran et al. ${ }^{2}$ The percentage of women who has undergone emergency cesarean section in present pregnancy, in relation to previous cesarean section indication were elderly primi $(4 / 4,100 \%)$, transverse lie $(1 / 1,100 \%)$, dystocia $(29 / 30$,
$96.66 \%)$, prelabor rupture of the membranes $(22 / 24$, $91.7 \%)$, oblique lie $(6 / 8,75 \%)$, postdated $(16 / 28$, $57.14 \%)$, breech $(26 / 54,48.1 \%)$, pregnancy induced hypertension $(10 / 44,22.72 \%)$, fetal distress $(13 / 62,21 \%)$ and fetal growth restriction (4/22, 18.2\%). Of all attempting VBAC, $24.5 \%$ will fail as reported in the study. ${ }^{6}$ Another study by Ugwu GO et al recorded that $50 \%$ successful vaginal birth rate after caesarean section and $50 \%$ failure rate. $^{7}$ In the present study, $52.3 \%$ $(145 / 277)$ women who attempt to deliver vaginally after one previous cesarean section was successful and $47.7 \%$ (132/277) women required emergency cesarean section which is almost similar to the study mentioned above. Abdelazim IA et al recorded that mean gestational age was significantly lower in the successful TOLAC (trial of labor after caesarean section) group compared to the unsuccessful group $(37 \pm 0.04$ versus $38.5 \pm 0.03){ }^{8}$ In the present study authors also found that VBAC was successful at gestational age of 37-38 weeks compared to $\geq 39$ weeks (Table 2). An inter-delivery interval of $\leq 24$ months was associated with scar dehiscence which was more compared with inter-delivery interval of $>24$ months $(4 / 22,18.18 \%$ versus $8 / 255,3.13 \%, p=0.005)$ in the present study. Scar dehiscence was diagnosed during cesarean section. Per vaginal check for scar integrity done after successful vaginal delivery and symptomatic dehiscence was nil. The number of women with an interdelivery interval $<2$ years was significantly higher in the unsuccessful TOLAC group compared to successful group, as mentioned by Abdelazim IA et al. ${ }^{8}$ RCOG Recommended, Green-top guideline no.45 October 2015 states that women delivering within 18 to 24 months of a caesarean section should be counselled about an increased risk of uterine rupture in labour. ${ }^{4}$ Upper segment uterine scar, improper apposition with tight uterine margin suturing, infection, poor nutritional status and short inter delivery interval are the factors for poor healing of uterine scar.

Among the failed VBAC women, 12 cases of scar dehiscence were found at cesarean section of which 7 had baby weight more than $3 \mathrm{~kg}(3.32 \pm 0.14)$ and 5 had less than $3 \mathrm{~kg}(2.82 \pm 0.09)$ in the present study. Abdelazim IA et al et al recorded that an estimated fetal weight $\leq 3.5 \mathrm{~kg}$ was associated with successful trial of labor after caesarean. ${ }^{8}$ Neonatal complications in the failed VBAC group were hypoxic-ischemic encephalopathy (6), jaundice (4), sepsis (2), early neonatal death (10) and low Apgar scores at 1 minute (6) in the present study which was more compared with successful VBAC. Early neonatal death was significantly more in the failed VBAC group in the present study $(\mathrm{p}=0.025)$. Two neonatal death in the successful VBAC group was due to sepsis (1) and respiratory infection (1). Four baby had birth injury in the successful VBAC group due to ventouse application.

Apgar scores less than 7 in the first minute were more frequent in those with failed VBAC than vaginal delivery (successful VBAC); however, the difference was not statistically significant as recorded by Ugwu GO et al. ${ }^{7}$ In 
the present study Apgar scores less than 7 in the first minute were not significant between the successful VBAC and failed VBAC group $(\mathrm{p}=0.411)$. Tan et al and Ball et al reported increases in risks of neonatal morbidities and hypoxic ischemic encephalopathy after an unsuccessful TOLAC. ${ }^{9,10}$

In another study by Abdelazim IA et al recorded that there was significant neonatal intensive care admission in the failed VBAC due to birth asphyxia, meconium aspiration and sepsis compared to the successful group. ${ }^{8}$ In the present study there were two still birth in the failed VBAC group, one was associated with scar dehiscence and meconium stained liquor amnii and other one with pregnancy induced hypertension. Kok $\mathrm{N}$ et al reported birth trauma, Apgar scores $<7$, still birth and neonatal death were more in the second birth after caesarean in their study. ${ }^{1}$ In present study, authors found that scar dehiscence and hypoxic-ischemic encephalopathy were more in the failed VBAC group. Of all 145 Successful VBAC, $84(57.9 \%)$ delivered spontaneously and 61 $(42.1 \%)$ women required ventouse application to cut short second stage of labor.

In the study by Gupta P et al found that incidence of scar dehiscence was significant following trial of labor than elective repeat LSCS (9.62\% versus $1.62 \%, \mathrm{p}=<0.005)$ which is almost similar to present study $(9.09 \%)$ in the failed VBAC group. ${ }^{11}$ They also noted that maternal morbidity in the form of fever, wound sepsis and blood transfusion were more in emergency LSCS following trial of labor which is also in accordance with the present study as shown in the Table 5. Ugwu GO et al recorded no cases of uterine rupture who attempt VBAC. ${ }^{7}$ Though no uterine rupture was noted in the present study, in two cases extension of uterine injury occurred during delivery of the baby for which hysterectomy was done (Table 5). No induction of labor or augmentation with oxytocin was done in the present study. Tan PC et al recorded trial of labor was associated with shorter hospital stay. ${ }^{9}$ In the present study authors also found that mean duration of hospital stay were significant in the failed VBAC compared to successful VBAC women.

\section{CONCLUSION}

Overall, women in active stage of labor at $370 / 7$ to 38 6/7 weeks of gestation with cephalic presentation who had previous caesarean section done for fetal distress, pregnancy induced hypertension and fetal growth restriction with inter-pregnancy interval of more than 24 months can be planned for VBAC trial. Scar dehiscence occurred in the failed VBAC. Early neonatal death and hospital stay were significant in the failed VBAC women.

\section{ACKNOWLEDGMENTS}

Authors thank Dr. Nirmalya Sinha, Associate Professor, Department of Community Medicine, Midnapore Medical College for analysing the data.

Funding: No funding sources

Conflict of interest: None declared

Ethical approval: The study was approved by the Institutional Ethics Committee

\section{REFERENCES}

1. Kok N, Ruiter L, Hof M, Ravelli A, Mol BW, Pajkrt E, et al. Risk of maternal and neonatal complications in subsequent pregnancy after planned caesarean section in a first birth, compared with emergency caesarean section: a nationwide comparative cohort study. BJOG. 2014;121:216-23

2. Balachandran L, Vaswami PR, Mogotlane R. Pregnancy Outcome in Women with Previous One Cesarean Section. J Clin Diagn Res. 2014;8:99-102.

3. ACOG Practice Bulletin \#115: vaginal birth after previous cesarean delivery. Obstet Gynecol. 2010;116:450-63.

4. RCOG Birth after Previous Caesarean Birth. Green-top Guideline No.45.2015.

5. Tessmer -Tuck JA, El-Nashar SA, Racek AR, Lohse CM, Famuyide AO, Wick MJ. Predicting vaginal birth after cesarean section: a cohort study. Gynecol Obstet Invest. 2014;77:121-6.

6. Srinivas SK, Stamilio DM, Stevens EJ, Odibo AO, Peipert JF, Macones GA. Predicting failure of a vaginal birth attempt after cesarean delivery. Obstet Gynecol. 2007;109:800-5.

7. Ugwu GO, Iyoke CA, Onah HE, Egwuatu VE, Ezugwu FO. Maternal and perinatal outcomes of delivery after a previous Cesarean section in Enugu, Southeast Nigeria: a prospective observational study. Int $\mathrm{J}$ Womens Health. 2014;6:301-5.

8. Abdelazim IA, Elbiaa AAM, Al-Kadi M, Yehia AH, Nusair BM, Faza MA. Maternal and obstetrical factors associated with a successful trial of vaginal birth after cesarean section. J Turk Ger Gynecol Assoc. 2014; $15: 245-9$.

9. Tan PC, Subramaniam RN, Omar SZ. Labor and perinatal outcome in women at term with one previous lower-segment Cesarean: A review of 1000 consecutive cases. ANZJ Obstet Gynecol. 2007;47:31-6.

10. Ball E, Hinshaw K. The current management of vaginal birth after previous cesarean delivery. The Obstet Gynaecol. 2007;9:77-82.

11. Gupta P, Jahan I, Jograjiya GR. Is vaginal delivery safe after previous lower segment caesarean section in developing country? Niger Med J. 2014;55:260-5.

Cite this article as: Bera SN, Sharma PP. Vaginal delivery at term with previous one cesarean section: is it safe?. Int J Reprod Contracept Obstet Gynecol 2018;7:3147-51. 